\title{
Erratum to: Acute health problems in African refugees
}

\section{Ten years' experience in a Swiss emergency department}

Carmen A. Pfortmueller · Fabienne Graf · Malek Tabbara · Gregor Lindner •

Heinz Zimmermann · Aristomenis K. Exadaktylos

Published online: 9 August 2013

(C) Springer-Verlag Wien 2013

Erratum to: Wien Klin Wochenschr (2012) 124:647-652 DOI 10.1007/s00508-012-0227-9

In the published article, the family name of the co-author Malek Tabarra is not given correct. The correct name is: Malek Tabbara

The online version of the original article can be found under doi: http://dx.doi.org/10.1007/s00508-012-0227-9

C. A. Pfortmueller, M.D. ( $\square)$

Department of General Internal Medicine, Inselspital Bern, Bern, Switzerland

e-mail: cpfortmueller@gmail.com

F. Graf $\cdot$ M. Tabbara $\cdot$ G. Lindner $\cdot$ H. Zimmermann Department of Emergency Medicine, Inselspital Bern, Bern, Switzerland

e-mail: fabienne.graf@students.unibe.ch

M. Tabbara

e-mail: malektabbara@gmail.com

G. Lindner

e-mail: lindner.gregor@gmail.com

H. Zimmermann

e-mail: heinz.zimmermann@insel.ch

A. K. Exadaktylos, M.D., F.C.E.M.

Department of Emergency Medicine, University Hospital Bern, 3010 Bern, Switzerland

e-mail: exadaktylos@exadaktylos.ch 